\title{
Light as an ambient material in transformative urban "night" spaces
}

\author{
Meliti D. Dikeos ${ }^{1}$ \\ ${ }^{1}$ Department of Architecture, Wentworth Institute of Technology, Boston, USA
}

\begin{abstract}
This study explores the subject of design and community engagement with regard to light as a transformative material in urban "night" spaces. Four unique case studies, each of which originated under the auspices of meeting specific site purposes or needs, nevertheless all represent the successful coming together of design, local suitability and ultimately, community support and participation.
\end{abstract}

\section{Introduction}

The mysterious and spiritual qualities of natural light and shadow have long been studied by artists and architects alike. Louis I. Kahn poetically wrote about "silence and light" and how "Greek architecture taught [him] that the column is where the light is not, and the space between is where the light is. It is a matter of no-light, light, no-light, light." [1] Whether in the temples of the Greco-Roman world or the religious buildings belonging to faiths around the globe, natural light has always been understood as having transformative spiritual qualities that designers hope to attain in secular structures as well. However, what happens in darkness, in the city, when the sun can not affect the aura of a place? At night, light is often seen as an artificial necessity, rather than as the carrier of a more powerful, experiential message. One can argue that design creativity is limited because of the understandable concern and focus on nocturnal, urban safety. The author of this paper proposes to investigate how architecture and the public, together, can create transformative urban "night" spaces through the innovative use of artificial light.

In her 1961 book, The Death and Life of Great American Cities, writer Jane Jacobs argued that it is a city's role to ensure safety and that good public lighting is essential. She recognized the different personalities of a city during daytime versus nighttime hours and emphasized the importance of street life with people as the "eyes on the street," "unconscious[ly] policing." [2] As an activist herself, Jacobs believed in the power of community wisdom and engagement as a means toward urban improvement. Although her ideas may seem mainstream today, the public as a partner for design and community pride cannot be underestimated. As such, this study will seek to emphasize the active participation of local residents and business people in understanding nocturnal urban problems and insight in how to solve them. Case studies of atmospheric community and architect designed "night" projects with varying financial means will be reviewed as a base against which further exploration can be generated in both professional practice and academia. 


\section{Community developed and designed nightscapes}

\section{1 “Pittaki Street” | Athens, Greece}

The gritty Psyrri neighborhood in downtown Athens, Greece is known for its night life, alternative Greek eateries, live music scene, offbeat shops, and more recently, for a creative light art installation. Since the economic crisis of 2008, Athens, and the country as a whole, has battled severe austerity measures that have weighed on both the financial and emotional livelihood of its citizens. In an effort to conserve money and energy to meet demanding taxes, many residents have turned the lights off at their building entries, darkening both their surroundings and their state of mind. Pride of place has diminished and some streets, like the more industrial Pittaki Street in the Psyrri neighborhood, had become inhospitable, run-down alleys of trash, criminal activity, and graffiti. Frustrated by their depressed urban condition, in 2013 residents took on the challenge of regenerating the life of the neighborhood by creatively re-illuminating this darkened street, symbolic of many.

The Greek non-profit group Imagine the City, in partnership with the visual arts group Before Light, organized the collection of unwanted ceiling lights, sconces, old lanterns, and other creative shades, including personal hats, to fulfill a simple design vision. The motley donations were weatherproofed, wired for low consumption LED bulbs, and strung across the street from building to building (Fig. 1).

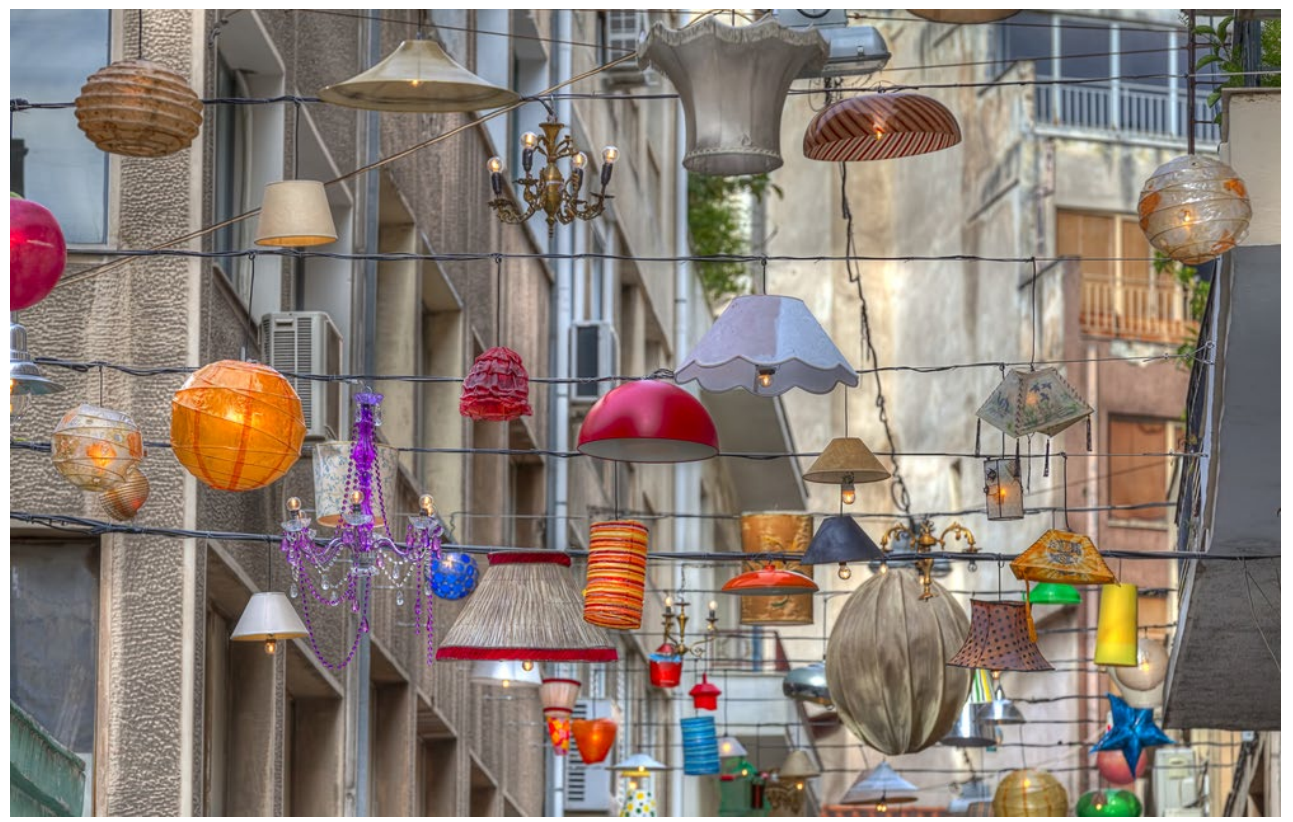

Fig. 1. Pittaki Street - Athens, Greece | C Anastasios71

What started off as a community experiment with a targeted six-month installation has since grown into a unique landmark that shows no signs of diminishing after six years. With sponsorship by Coca-Cola and its "Believe in a Better Tomorrow" campaign, this remarkably modest project of $\$ 40,500$ has rejuvenated the community with not merely a sense of safety, but also one of pure joy. Athenians have been brought back outdoors in Psyrri with the help of numerous nighttime cultural activities held here. Although Project Manager Stephania 
Xydia of Imagine the City recognizes the humble character of this installation, she also recognizes its influence: "This is very small scale; it's not a revolution...But since the (economic) crisis, more Greeks want to be involved in the revival of urban spaces." [3] This modest project can be seen as a "beacon of hope" and as a case study for further partnerships of communities, non-profits, and designers.

\section{2 “Universal Lantern” | Cartagena, Columbia}

A comparable case study to that of Pittaki Street can be found in Cartagena, Colombia, where a collaborative process with locals, including architecture students, and lighting specialists from the multinational Arup Group reactivated streets in the Getsemani neighborhood. Remarkably similar to the once rough Psyrri neighborhood, Getsemani was formerly a place of drugs, prostitution, and spotty crime. On the edge of Cartagena's historic district, it is now considered the trendy locale for restaurants, music, and mural art. However, as in Athens, while the public squares enjoyed a nightlife common to larger, thriving urban gathering areas, the side streets found themselves in the dark with limited social interaction.

Seen as untapped, yet promising areas for greater residential engagement, the design team - led by Don Slater, co-director of the Configuring Light research group at the London School of Economics, Arup lighting leader Leni Schwendinger, Universidad Jorge Tadeo Lozano and Despacio, PLANE-SITE managing director Andres Ramirez, Italian lighting manufacturer iGuzzini, and numerous other participants - hosted neighborhood gatherings and workshops to understand the specific characteristics of these streets and the inhabitants. Their process developed into a strategy of night lighting through what was called a "universal lantern," a concept based on the use of traditional lanterns. [4] (Fig. 2).

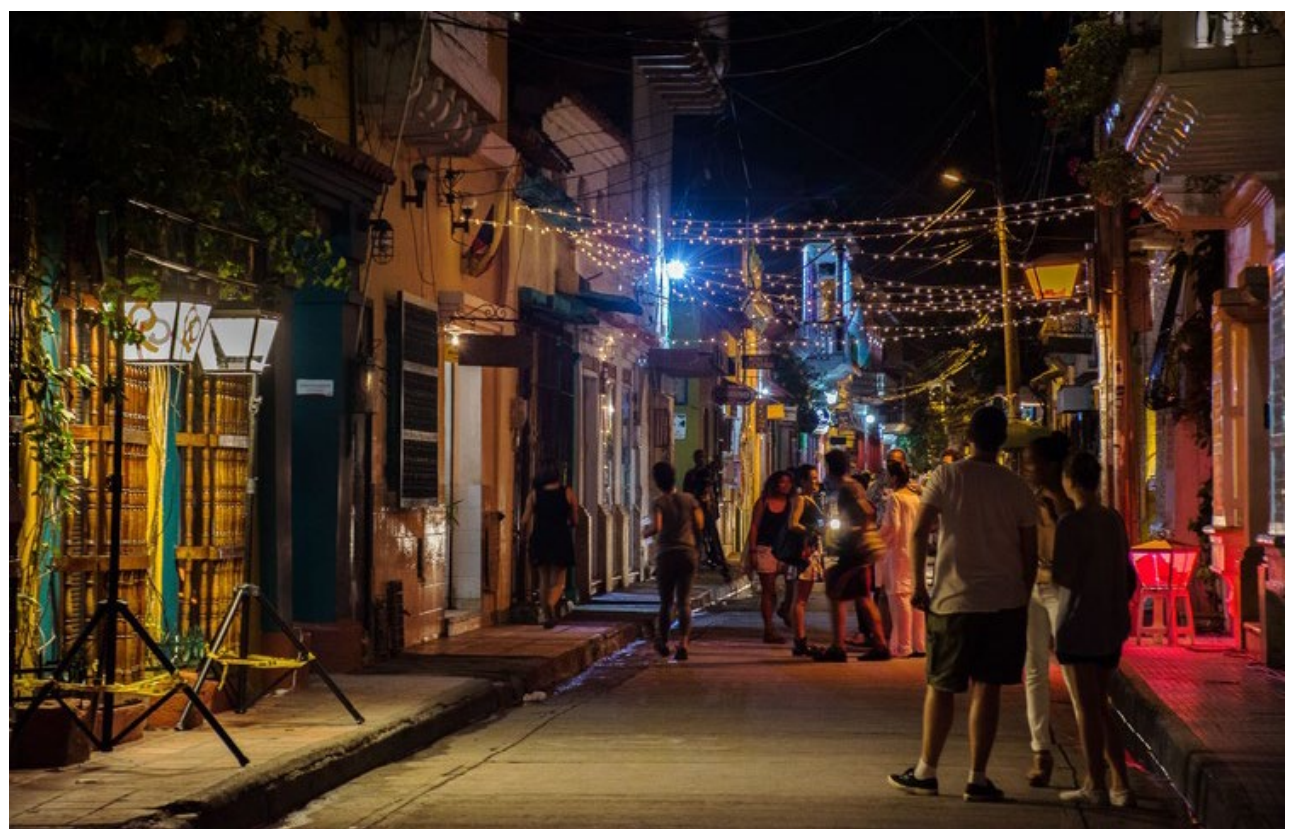

Fig. 2. "Universal Lantern" - Cartagena, Columbia | C Dr. Don Slater, LSE

Private residential building faces and public commercial storefronts were the backdrop against which these "universal lanterns" of varying colors and creative patterns were installed. They were arranged in a variety of ways - off balconies, on low stools, on tripod- 
like stands, along building faces, and stitched together with delicate string lights crossing the street. As in Athens, this spare installation in Cartagena proved to be an effective method for social interaction that originated from a process of collaborative community engagement and concluded with a sense of neighborhood ownership.

\section{Architect designed nightscapes}

\section{1 "White Night, White Noise" | Athens, Greece}

Interestingly, the Pittaki Street project became a physical reality in 2013, almost a decade after the 2004 Summer Olympics in Athens, an event that intensified Greece's economic difficulties. During the feverish preparation that preceded the Games and within walking distance of the Psyrri neighborhood, Boston-based architects Höweler + Yoon were selected by the Athens Olympic Committee for a temporary (18-day) art installation sited in the more distinguished and renowned Makrigianni neighborhood at the base of the Acropolis. Their celebrated design, titled White Night, White Noise, was a sensor-activated light installation on a platform with a field of fiber optic stalks. (Fig. 3).

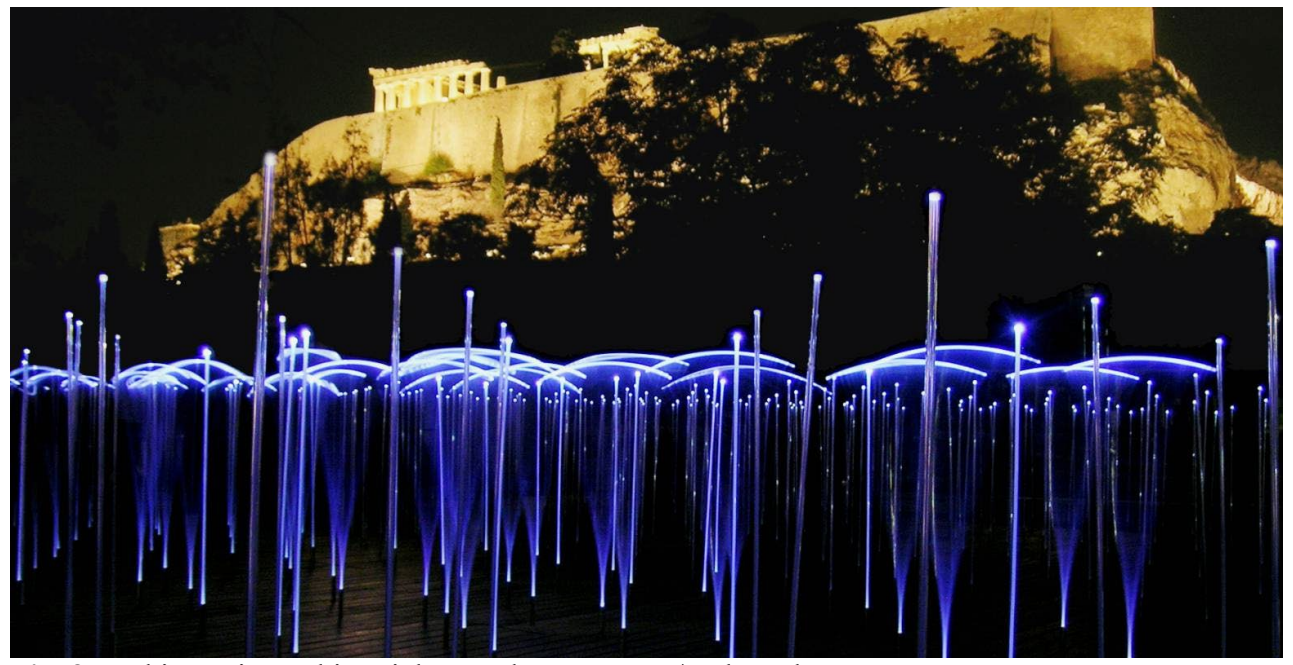

Fig. 3. "White Noise, White Light" - Athens, Greece | C) howeleryoon.com

The movement of pedestrians entering the field would trigger white light from the LEDs and noise from associated speakers below. Playful and mysterious qualities of flickering light and sound were generated during the dark hours of the night, under the steady glow of the Parthenon itself.

Höweler + Yoon's sophisticated technical detailing at this stately, tourist-filled site seems to share little in common with the less refined Pittaki or Gensemali Street projects. However, despite obvious differences, these three designs are urban experiments that share a similar message regarding the potential of nocturnal light as a generator of community and civic engagement. Architects Eric Höweler and Meejin Yoon described their Athens project in a manner that furthers the significance of public reciprocity in design ventures: 
"By acknowledging the unpredictability of the architectural encounter, designers can capitalize on the public realm as a fertile testing ground for interactivity, explicitly relying on public participation and play for the completion of various projects. These projects could be called 'open source': they invite multiple participants to co-produce unanticipated outcomes in an evolving scenario of scripted and unscripted behaviors." [5]

The body's interaction with this particular piece generated varying qualities of light and noise, from darkness and silence to steady and sound-filled. The uncertainty of what is to be experienced in this nocturnal scene are suggestive of Louis Kahn's words regarding daylight and its ability to inspire awe. While the quality of light in the White Night, White Noise installation embrace these more poetic qualities, the charm of the eclectic light in Athens' Pittaki and Cartagena's Getsemani neighborhoods are equally significant. Although the projects themselves were initiated from differing starting points, resources, and stakeholders, they all share a common thread in their value of "public participation and play."

\section{2 "Luminous Drapes" | Kuwait City, Kuwait}

Unlike the physically activated, playful installation of Höweler + Yoon's "White Noise, White Light," the architectural firm Studio Toggle designed a temporary installation for "The Human Capital 2018" cultural forum in Kuwait City, Kuwait as a place to socialize through rest, rather than movement. In contrast to gathering in a place of passage, whether through "lanterned streets" or a "lit field," this piece creates a place of both daytime and night-time rest through a series of minimal pavilion structures. The piece itself was made from a "kit of parts" that included construction scaffolding, tube lights, drapes, and benches (Fig. 4).

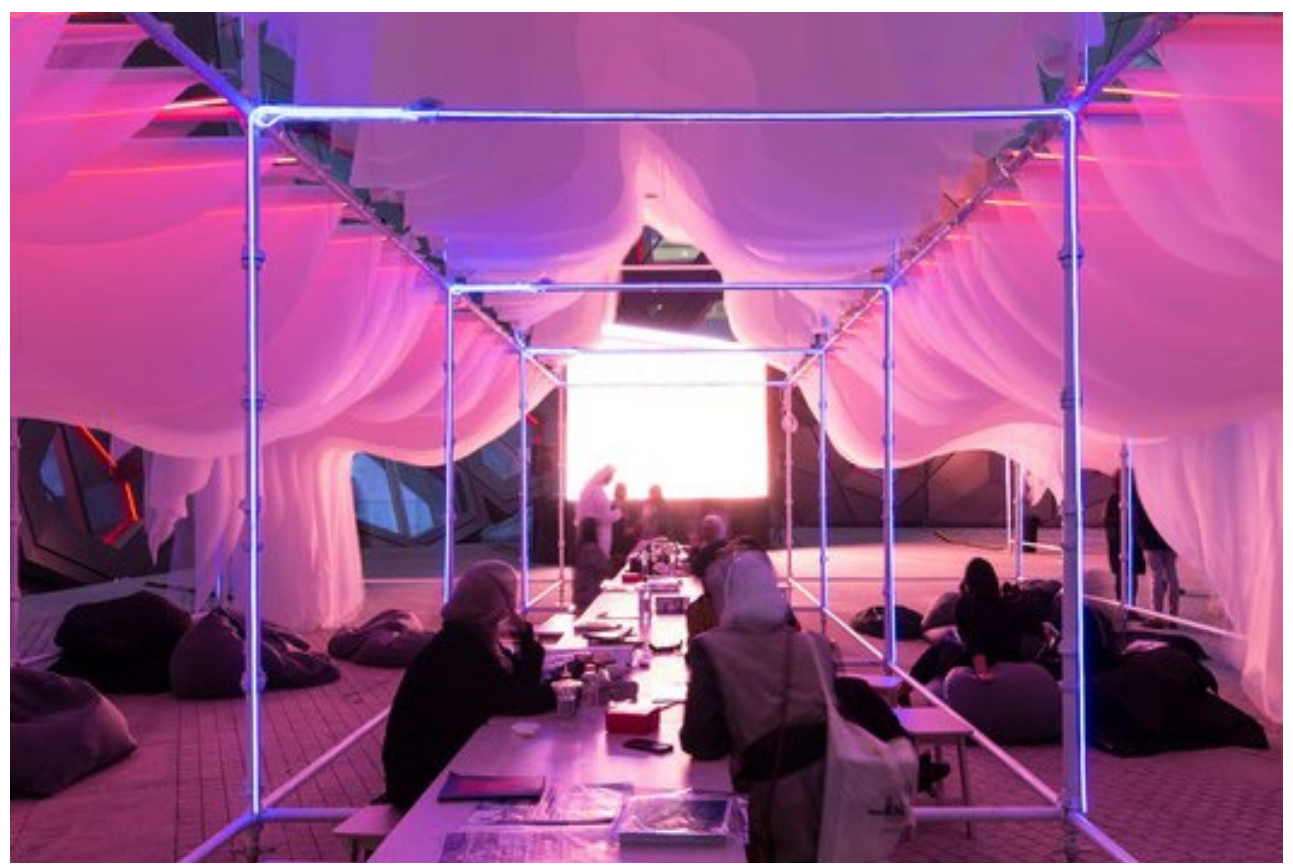

Fig. 4. "Luminous Drapes" - Kuwait City, Kuwait | (C) Gijo Paul George 
Through Nuqat, a Kuwait nonprofit organization, the architects were challenged by the broad directive of designing an outdoor gathering place in the expansive plaza of the newly opened Sheikh Jaber Al-Ahmad Cultural Center. To do so, they strategized a series of rooms with drapes laser-cut and arranged in ways that would encourage the public to "collaborate," "lounge," "socialize," "dine," and "meet," all terms used in the actual designers' diagrams. At night, when the pavilions were lit, these outdoor rooms assumed a romantic, almost alluring quality, with the softness of the layered drapes creating a light, billowy mass. The name of the installation, "Luminous Drapes" appropriately defines this lit pavilion that, in the architects' own words, "changes its ambience and makes for a dynamic space," through the use of light as a "sculptural medium." [6] The simple detail of outlining the scaffolding with tube lights shows an understanding of how a shared, yet intimate, nighttime environment can originate through an inventively low-tech and low-cost approach. From natural light in daytime hours to artificial light at night, the character and atmosphere of the space changed.

\section{Conclusion}

While there are numerous case studies worthy of study regarding the nocturnal urban condition and the transformative qualities of artificial light, these four were selected for the thematic stories they share. In each of these urban locations - whether in Athens, Greece, Cartagena, Colombia, or Kuwait City, Kuwait - the nighttime environment was reinvented in ways that go beyond the status quo by putting artistic prowess at the forefront. In the Psyrri and Getsemani neighborhoods, urban weaknesses inspired activists, non-profit organizations, lighting manufacturers, architecture students and professors, to collaborate. Through limited financial means, people were brought together outside, on the streets, in a way that regenerated the community. In the more refined and touristy neighborhoods of Höweler + Yoon's Athens installation or Studio Toggle's Kuwait City installation, one also sees a responsive understanding for unique, social place-making at night. Regarding "White Noise, White Light," Meejin Yoon stated that:

"The most amazing thing was how public this project was... One of the most incredible moments was the opening night when an elderly Greek woman came with roses for the project team and said, 'Thank you so much for bringing this to Athens. Thank you from the city."' [7]

Despite the temporary nature of this installation, the project clearly brought not only a sense of beauty and pride to the community, but also a sense of local unity and grace in the midst of a larger global event such as the Olympics. In contrast, although the long-term effects of groundswell projects which come to meet less specific but nonetheless vital neighborhood challenges are more difficult to measure, they are no less important to a locale's vitality. This is even more significant when the results have a creative and artistic bent to them rather than solely fulfilling a utilitarian requirement. Although there is much debate regarding the negative effects of light pollution, each of these projects embodies a delicate balance between nocturnal light and all it represents in terms of safety, showmanship, and social gathering. The sensitive use of artificial light as an "ambient" material, along with an inspired design vision and public participation, becomes a powerful tool, which, as Jane Jacobs reminds us, can serve to revitalize night street life and community. 


\section{References}

1. J. Lobell, L. Kahn. Between Silence and Light: Spirit in the Architecture of Louis I. Kahn. Distributed in the U.S. by Random House (2000, c1979) www.azquotes.com/quote/645512, accessed on 1/31/19

2. Jacobs, Jane. The Death and Life of Great American Cities. New York : Modern Library (1993)

3. T. Hsu, "Whimsical Project Puts Athens' Pittaki Street in a Better Light" (Los Angeles Times, October 11, 2013)

4. T. Forde, "Smart Everyday Nighttime Design Aims to Use Light as a Means to Build Better Communities" (Archdaily, September 28, 2017)

5. E. Höweler, M. Yoon, "Verify in Field" (Perspecta, Vol. 42, pp.163-167, 2010)

6. Studio Toggle, "Luminous Drapes: Experimental Urban Pavilion 2018" https://studiotoggle.com/portfolio/exhibition/luminous-drapes

7. E. Donoff, "White Noise, White Light" (Architectural Lighting, March 8, 2007) 